\title{
ENTRE O FRACASSO E A TRAIÇÃO: UMA MIRADA IMPERFEITA À TRADUÇÃOi
}

\author{
Joana Bosak de Figueiredo - UFRGS
}

Joana Bosak de Figueiredo é doutoranda em Literatura Comparada no Programa de Pós-Graduação em Letras da Universidade Federal do Rio Grande do Sul, bolsista da CAPES.

RESUMO: Dans les etudes sur la traduction, aujourd'hui, les mots et les idées comment fracas, fidelité et trahison ne sont plus considerées suffisant. Plus important ces't la idée de negotiation qui la de trahison, porquoi la traduction opera une lecture en profundité de le texte y cherche la comunication entre deux langages et cultures differentes. La traduction ces't une practique ici vue qui reordre le langage chaque fois qui si a fait, tournent etterne, de cette façon, le texte qui est traduit. Dans les idées ici exposées, auteurs comment Ortega y Gasset, Umberto Eco, Valery Larbaud, Jorge Luis Borges, Haroldo de Campos et autres plus recentes son rapidement examinés dans quelques regardes toujours incompletes sur la traduction, pourquoi la practique marche, toutefois, attentent par une nouvelle interpretation.

PALAVRAS-CHAVE: Tradução. Negociação. Transcriação. Alheio.

Não há fatos, apenas interpretações. Friedrich Nietzsche

A afirmativa secular de Nietzsche cai como uma luva ao refletirmos sobre as questões concernentes aos estudos da tradução na atualidade. Pontos como a mobilidade dos sentidos e as negociações que o tradutor têm de fazer com o texto fonte para atingir os seus objetivos já são considerados como algo indissociável da prática tradutória nos estudos culturais de maneira geral. As reflexões recentes na área das teorias da tradução, o aporte do multiculturalismo, da crítica pós-colonial e as pesquisas cada vez mais recorrentes sobre identidade e alteridade; alteraram a rota dos estudos tradutórios, colocando-os cada vez mais no centro dos estudos culturais como objeto altamente condensado de todas essas novas perspectivas. Esses estudos, por sua vez, apontam, como não poderia deixar de ser, para a relativização de verdades e culturas antes absolutas ao se definir critérios e métodos tradutórios e de análise.

Tomados, no passado, quase como que conceitos em tradução, termos tais como fracasso, (in)fidelidade e traição já não podem mais ser considerados como medida da qualidade das traduções, mas sim como frágeis limites anteriormente impostos de um ponto de vista estritamente literal que, muitas vezes, as traduções buscavam, já que a própria idéia do que é tradução tem sido ressemantizada no decorrer dos séculos em que essa existe, como prática e reflexão sobre o seu objeto, desde os tempos de São Jerônimo ii. As idéias de similaridade e de veracidade também sofreram uma reviravolta em seus significados. Ensaios e práticas tradutórias como os de Haroldo de Campos, tendo como princípio a transcriação literáriaiii como toda uma recomposição dos imaginários presentes no exercício tradutório, permitem uma mirada outra que nos mostra como a tradução, mais do que um compromisso estrito com o original pode ser, ela mesma, um outro "original", pois nos dizeres do próprio Haroldo, "se o poeta é um fingidor, o tradutor é um trans-fingidor,'iv .

O professor Carlos García Gual, em sua conferência sobre a tradução de clássicos gregos nos $X$ Encuentros Complutenses en torno a la traducción, evento que teve por mote os quatrocentos anos de Don Quixote e os problemas e perspectivas da tradução de clássicos ${ }^{\mathrm{v}}$, afirmou que traduzir é ler em profundidade e, mais que tudo, a tradução deve fazer dos textos veículos de comunicação universal; ferramentas para se ler melhor. Nesse sentido, o professor-tradutor está pensando no alcance da tradução e em suas possibilidades de fazer-se ponte entre as culturas. Para tanto, a tradução não pode ser "congelada" por princípios rígidos e datados, os quais impedem a propagação dos textos, inclusive clássicos, por longos períodos de tempo. É a idéia de que as traduções são mais do que necessárias, imprescindíveis, pois conferem sobrevida e eternidade aos textos com seu olhar atualizado.

Muito antes, o filósofo, também espanhol, José Ortega y Gasset, já na década de 1930, apesar de utilizar o termo fracasso em seu clássico ensaio "Miséria y esplendor de la traducción"vi se rende à noção de que a tradução longe de ser infalível, será sempre necessária e imperfeita, porque o que está em jogo é, inexoravelmente, a escolha de um aspecto - forma - em detrimento de outro - conteúdo ${ }^{\text {vii }}$. Então, de que tipo de fracasso se está falando? 
Segundo Michael Wood, o fracasso não é absoluto e nem definitivo, pois palavras, imagens e estilos podem ser traduzidos de maneira persuasiva, e mesmo a perda de algumas conotações, na passagem de uma língua a outra pode ser considerada como

[...] el vislumbre de un nuevo significado o una resonancia que aparece en el preciso espacio que se abre entre los idiomas. [...] Nuestro criterio para medir el acierto no puede ser la transmisión perfecta de todos los sentidos de un texto o de un discurso. Esto no sería en absoluto una traducción, sino una réplica inconcebible, casi como ocurre en un relato de Borges donde el mapa de un imperio resulta ser tan grande como el imperio mismo."viii

Ou seja, aspectos como a escala, indiretamente apontada por Borges, na metáfora do mapa, e do ponto de vista, são fundamentais para que se perceba a dificuldade de se repetir de forma exatamente igual o que se diz em duas línguas distintas, em contextos distintos e a públicos separados por épocas e geografias diferentes. Se a tradução é uma segunda vida do texto, como sugere Borges ${ }^{\mathrm{ix}}$, ela será sempre diversa da "versão original" e por isso mesmo sempre alvo de críticas e análises detalhadas de sua "falibilidade".

Para Efraín Kristal, leitor atento de Borges, a tradução é o processo "mediante el cual un escritor remodela una secuencia de palabras en otra" . Kristal pensa que a tradução ocupa um papel de muito maior vulto na obra de Borges que, por exemplo, os labirintos, espelhos e as enciclopédias dos quais o autor faz tanto uso, já que aquela é seu mais antigo substrato criador, sendo inclusive sua primeira obra a tradução de O Príncipe Feliz, de Oscar Wilde, em 1910, quando contava apenas nove anos de idade.

O próprio Borges, ao remeter-se ao processo criativo, relativiza as idéias de criação e imaginação. Para ele, a imaginação é uma memória imperfeita, porque humana, mas leal ao que ocorreu, por mais estranho e distante que possa parecer. E na leitura de Wood, imaginar o passado não é inventá-lo, mas encontrá-lo de uma maneira possível à falha e criativa memória humana. Dessa maneira, o próprio passado torna-se compreensível como um texto traduzido persistentemente ${ }^{\mathrm{xi}}$, resultante de reposições dessa memória já relativizada e distanciada ${ }^{\mathrm{xii}}$. Assim, fica ainda mais honesta a afirmação de Borges quando diz que as diversas traduções de um mesmo texto são perspectivas diferentes de um fato móvel, aliás, muito próximo do que diz Nietzsche, sobre os fatos e as interpretações. Além disso, distanciando-se de um maniqueísmo recorrente na avaliação das traduções nas teorias em geral, Borges nos diz que as traduções podem ser boas e más porque nem mesmo os textos originais são todos bons.

Dentro de uma conjuntura mais recente, na qual as mudanças no mundo atingem diretamente a questão da tradução, vemos outras opiniões sobre o tema. De forma atual e relativizada Umberto Eco propõe como teórico e prático da tradução uma mirada crítica ao tema em Dire quasi la stessa cosa - esperienze di traduzione $e^{\text {xiii }}$, seu livro publicado em 2003 sobre suas experiências como tradutor e autor traduzido. Já no prefácio propõe que a problemática pode estar centrada em dire, em stessa, ou em cosa, mas que o que mais the ocupa é o quasi.

Para Eco, então, "dire quasi la stessa cosa è um procedimento che si pone all'insegna della negoziazone", e o que será é negociado é justamente este quase. Qual é a quase mesma coisa que se diz em outra língua? É justamente a medida deste "quase" que permite toda esta discussão em torno dos limites de uma tradução ou das traduções em geral. Dependendo do enfoque, pode ocorrer uma "creación traicionera", como propõe Michael Wood ${ }^{\text {xiv }}$, ou uma forma de loucura, como sugere Maurice Blanchot ${ }^{\mathrm{xv}}$, um prazer e um deleite, segundo Valery Larbaud ${ }^{\mathrm{xvi}}$ ou ainda, uma dilaceração, conforme Florence Herbulot ${ }^{\text {xvii }}$.

A distância e a diversidade dos adjetivos tributados à tradução deixa apenas uma certeza em seus horizontes: a do caráter irremediavelmente contraditório da prática tradutória. É justamente essa contradição perene que torna a discussão tão constante e rica. À medida que o tempo passa, aumenta a importância da tradução e a quantidade de reflexões teorizantes sobre ela. Mesmo quando o teórico espanhol J. C. Santoyo ${ }^{\text {xviii }}$ lista um sem número de vezes em que as traduções não são lembradas como os textos originais e que o trabalho de tradutor de grandes escritores é sempre deixado à sombra de sua produção literária considerada "maior", ainda assim aponta para a existência desse "trabalho invisível" como bem pontua Kristal ${ }^{\text {xix }}$ ou de "protagonista silencioso da literatura", como sugere, sabiamente, Larbaud ${ }^{\mathrm{xx}}$.

De toda forma, a maior parte das reflexões atuais sobre a tradução colocam-na na via dos estudos culturais, que pretende ver a tradução como mediadora de culturas, espaços e tempos distintos, como discute Susan Bassnett em Moving across cultures: translation as intercultural transfe ${ }^{\text {,xi, }}$, de 1997. Ao retomar de forma crítica o trabalho de Itamar Even-Zohar, Bassnett situa o panorama dos estudos de tradução dentro da perspectiva pós-colonial, lembrando enfaticamente que os chamados estudos multiculturais em geral partem de territórios precisos: europeus e monolíngües, sendo quase sempre escritos em língua inglesa. Como forma de resistência a este tipo de padronização cultural no que deveria ser múltiplo, situa o Manifesto Antropofágico como tendo uma postura nitidamente póscolonial $^{\text {xxii }}$. É na digestão do substrato europeu e na assimilação daquilo que é considerado produtivo na cultura alvo em questão que se gesta uma nova forma de ver e de pensar o mundo. Para Susan Bassnett essa visão pode ser facilmente incorporada às teorias da tradução. A teórica insiste que "translation is, after all, dialogic in its very 
nature, involving as it does more than one voice. The study of translation, like the study of culture, needs a plurality of voices"xxiii.

Se a tradução é dialógica em sua própria natureza, seria raro se atendesse a um único ponto de vista e que, portanto, representasse uma verdade monológica e que tivesse uma unidade de sentido que a tornasse completamente "fiel" em sua literalidade. E mais, se a tradução é, como quer Bassnett, um estudo que envolve culturas diferentes e se faz plural em suas vozes, uma vez mais não se poderia exigir que atendesse a um sentido absoluto anteriormente predefinido e que não passasse pela negoziazone de que nos fala Eco. A reflexão citada de Bassnett reitera a posição, anteriormente defendida, de que fica cada vez mais anacrônico utilizar-se termos como fracasso e traição em tradução.

De todas as maneiras e independentemente do caso específico a ser estudado, "traduzir é uma aventura de descobrimento, na qual se há que descobrir um enigma"xxiv . Esse grande enigma pode ser o "dizer a mesma coisa em outra língua", o "como dizer" e a negociação que o tradutor tem de fazer com o texto e com a língua para "dizer" da forma mais adequada para que o leitor compreenda e obtenha o efeito e o sentido propostos pelo autor no texto fonte, ou ainda, como gostaria Haroldo de Campos, que esse texto traduzido seja um novo original transcriado pelo tradutor/autor/transfingidor. Mesmo com todos os esforços e as reflexões existentes, cada vez mais ricas e aprofundadas, com diálogos que transcendem as barreiras lingüísticas, as fronteiras culturais e os limites geográficos e que vão até o quase domínio de outros códigos e visões de mundo, a tradução segue marcada pela contradição perene e inerente a sua própria existência, já que o tradutor sabe estar sempre fazendo escolhas, pois línguas diferentes são resultado de embates sócio-culturais e históricos, nos quais o contexto sempre fala.

Para concluir - por enquanto -, é esse espaço preci(o)so á divagação e à imprescindível imaginação, que se abre entre os idiomas que se chama tradução. Segundo Umberto Eco, o nosso é um mundo de línguas perfeitas com cores imperfeitas, sendo sempre impossível defini-las e classificá-las completamente. Assim ocorre com o objeto da tradução, a língua. E, "se consultate qualquiasi dizionario vedrete che tra i sinonimi di fedeltá non c'è la parola esatezza. Ci sono piuttosto lealtà, onestà, rispetto, pietà. ${ }^{\mathrm{xxv}}$,

\section{REFERÊNCIAS BIBLIOGRÁFICAS}

BASSNETT, Susan. Moving across cultures: translation as intercultural transfer. In: Trasvases Culturales Literatura, cine, traducción 2. Vitoria: Universidad del País Vasco, 1997.

BLANCHOT, Michel. Traduzir. In: JORGE, Guilhermina (coord.) Tradutor dilacerado. Lisboa: Edições Colibri, 1997.

BORGES, Jorge Luis. Versiones homéricas. In: Obras Completas, tomo I. Barcelona. Círculo de Lectores, 1992.

CAMPOS, Haroldo. Tradução e reconfiguração do imaginário: o tradutor como transfingidor. In: COULTHARD, M. \& CALDAS-COULTHARD, C. R.. Tradução: teoria e prática. Florianópolis: Editora da UFSC, 1991. ECO, Umberto. Dire quasi la stessa cosa - esperienze di traduzione. Milano: Studi Bompiani, 2003.

GIJALBA CASTAÑOS, Covadonga. Lo que nos une, lo que nos separa; enfoque cultural de la traducción. In: PERDU HONEYMAN, Nobel-Augusto \& VILLORIA PRIETO, Javier (orgs.). La traducción: puente interdisciplinar. Almería: Universidad de Almería, 2001.

HERBULOT, Florence. O tradutor dilacerado. In: JORGE, Guilhermina (coord.) Tradutor dilacerado. Lisboa: Edições Colibri, 1997.

KRISTAL, Efraín. Invisible Work: Borges and Translation. Nashville: Vanderbilt University Press, 2002.

LARBAUD, Valery. Alegrias e benefícios do tradutor. In: JORGE, Guilhermina (coord.) Tradutor dilacerado. Lisboa: Edições Colibri, 1997.

. Sous l'invocation de Saint Jerôme. Paris: Gallimard, 1997 (1946).

ORTEGA Y GASSET, José. Miseria y esplendor de la traducción. In: Revista de Occidente, 1970.

SANTOYO, J. C.. Algunas preguntas (y quizá respuestas) sobre la relatividad y caducidad del texto traducido. In: PEGENAUTE, Luis (ed.). La traducción en la edad de Plata. Barcelona: PPU, 2001.

WOOD, Michael. Creaciones traicioneras. New Left Review. Numero 20, mayo/junio. Madrid: 2003.

Notas: 
${ }^{\mathrm{i}}$ O presente artigo é resultado parcial da pesquisa financiada pela CAPES, no acordo bilateral entre a Universidade Federal do Rio Grande do Sul e a Universitat de Barcelona, intitulado "Estudos de Literatura Comparada, Tradução e Terminologia: América Latina e Espanha", que ocorreu em meu estágio de doutoranda no exterior, com estância nas cidades de Barcelona e Madrid, de março a dezembro de 2003.

${ }^{\text {ii }}$ Autores que refletiram e ainda o fazem sobre a matéria da tradução, tais como Valery Larbaud e Umberto Eco, em contextos bastante distintos referem-se ao papel de quem consideram o patrono dos tradutores, o primeiro tradutor da Bíblia: São Jerônimo. Ver: LARBAUD, Valery. Sous l'invocation de Saint Jerôme. Paris: Gallimard, 1997 (1946) e ECO, Umberto. Dire quasi la stessa cosa - esperienze di traduzione. Milano: Bompiani, 2003.

iii O ensaio referido é: Tradução e reconfiguração do imaginário: o tradutor como transfingidor. In: COULTHARD, M. \& CALDASCOULTHARD, C. R. Tradução: teoria e prática. Florianópolis: Editora da UFSC, 1991, e a prática tradutória exemplar pode ser a própria que se segue ao ensaio teórico.

iv Idem, ibidem.

${ }^{\mathrm{v}}$ Esses encontros ocorrem na Universidad Complutense de Madrid sem uma regularidade exata - em geral são bienais - e são dos eventos mais importantes da área na Espanha. Os encontros ocorreram de 12 a 15 de novembro de $2003 \mathrm{em}$ Madrid e o professor citado é o especialista em grego da própria UCM; sua conferência intitulou-se: "En torno a la traducción de los clásicos griegos: apuntes filológicos". Os anais ainda não encontram-se disponíveis. Ver site: www.ucm.es/info/iulmyt.

${ }^{\text {vi }}$ ORTEGA Y GASSET, José. Miseria y esplendor de la traducción. In: Obras Completas. Madrid: Editorial Revista Occidente, 1970.

${ }^{v i i}$ Para Eco é a escolha entre esses aspectos e as palavras a serem utilizadas no processo que definem o que irá tratar como negoziazone, a principal operação, segundo ele, que se faz numa tradução.

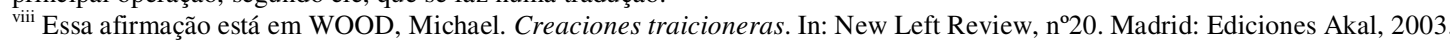

${ }^{i x}$ BORGES, Jorge Luis. Versiones homéricas. In: Obras Completas, tomo I. Barcelona: Círculo de Lectores, 1992.

${ }^{x}$ KRISTAL, Efraín. Invisible Work: Borges and Translation. Nashville: Vanderbilt University Press, 2002.

${ }^{x i}$ WOOD, op. cit., p.185.

xii $\mathrm{O}$ escritor português José Saramago, em $O$ Evangelho Segundo Jesus Cristo, faz uma bonita metáfora sobre o tempo, a história e as interpretações: “... Foi ontem, e é o mesmo que dizermos, Foi há mil anos, o tempo não é uma corda que se possa medir nó a nó, o tempo é uma superfície oblíqua e ondulante que só a memória é capaz de fazer mover e aproximar”. São Paulo: Companhia das Letras, 1997, p. 168.

xiii Milano: Bompiani, 2003.

${ }^{\text {xiv }}$ Op. Cit.

${ }^{x v}$ Maurice Blanchot discute a questão em: Traduzir. In: JORGE, Guilhermina (coord.) Tradutor dilacerado. Lisboa: Edições Colibri, 1997.

${ }^{\text {xvi }}$ Ver LARBAUD, Valery. Alegrias e benefícios do tradutor. In: JORGE, Guilhermina (coord.) Tradutor dilacerado. Lisboa: Edições Colibri, 1997 e a obra já citada, Sous l'invocation de Saint Jerôme. Paris: Gallimard, 1997 (1946).

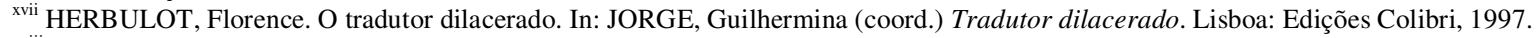

${ }^{\text {xviii }}$ SANTOYO, J. C.. Algunas preguntas (y quizá respuestas) sobre la relatividad y caducidad del texto traducido. In: PEGENAUTE, Luis (ed.). La traducción en la edad de Plata. Barcelona: PPU, 2001.

${ }^{\text {xix }}$ KRISTAL, op. cit.

${ }^{x x}$ Valery Larbaud define o tradutor dessa forma em: Sous l'invocation de Saint Jerôme. Paris: Gallimard, 1997 (1946).

${ }^{x x i}$ Ver: BASSNETT, Susan. Moving across cultures: translation as intercultural transfer. In: Trasvases culturales Literatura cine traducción 2. Vitoria: Universidad del Pais Vasco, 1997.

xxii ANDRADE, Oswald de. Manifesto Antropofágico. In: A Utopia Antropofágica. São Paulo: Editora Globo, 1995 (2ª ed.)p. 47 - 52.

xxiii BASSNETT, op. cit., p. 19.

${ }^{\text {xxiv }}$ GIJALBA CASTAÑOS, Covadonga. Lo que nos une, lo que nos separa; enfoque cultural de la traducción. In: PERDU HONEYMAN, NobelAugusto \& VILLORIA PRIETO, Javier (orgs.). La traducción: puente interdisciplinar. Almería: Universidad de Almería, 2001.

${ }^{\mathrm{xxv}}$ ECO, op. Cit., p. 364. 